\title{
Higher preoperative pain catastrophizing increases the risk of low patient reported satisfaction after carpal tunnel release: a prospective study
}

\author{
Sebastian Breddam Mosegaard ${ }^{1,2^{*}}$ (D) Maiken Stilling ${ }^{1,2}$ and Torben Bæk Hansen ${ }^{1,2}$
}

\begin{abstract}
Background: Carpal tunnel syndrome is a common upper-limb nerve compression disease. Carpal tunnel syndrome can lead to several symptoms such as tingling or numbness, pain in the hand or wrist, and reduced grip strength. Based on demographic characteristics, patient reported outcome measures, and with special attention to pain catastrophizing, the purpose of this study was to identify risk factors for low patient-reported satisfaction following surgical treatment of idiopathic carpal tunnel syndrome.

Methods: A total of 417 hands from 417 patients (64. 5\% females) with a mean age of 58. 0 years were included in this 1year prospective follow-up study. We collected preoperative data on disability using the Disability of the Arm, Shoulder and Hand questionnaire (DASH), quality of life using the EuroQol-5D (EQ-5D), pain catastrophizing using the Pain Catastrophizing Scale (PCS) and distal motor latency. Data on DASH score, EQ-5D, and patient satisfaction was collected 12 months postoperatively. Wilcoxon matched-pairs signed-rank test was used to test for difference in preoperative and postoperative DASH and EQ-5D score. Risk factors for low postoperative patient reported satisfaction was examined using stepwise multiple logistic regression analysis.
\end{abstract}

Results: We found a general improvement in patients' DASH scores (12.29 [95\% Cl: 10.65-13.90], $p<0.001)$ and EQ-5D (0.14 [95\% Cl: $0.13-0.16], p<0.001)$ from preoperative to 12 months postoperative. In the fully adjusted multiple regression analysis we found a statistically significant effect of preoperative PCS on patient reported satisfaction with $\mathrm{OR}=1.05(p=0.022)$, for a one unit increase in preoperative PCS. There was no statistically significant predictive effect of preoperative EQ-5D $(p=0.869)$, DASH $(p=0.076)$, distal motor latency $(p=0.067)$, age $(p=0.505)$ or gender $(p=0.222)$.

Conclusions: Patients improved in both DASH and EQ-5D from preoperative to 12 months postoperative. Higher preoperative PCS seems to have a negative effect on postoperative patient reported satisfaction after carpal tunnel release.

Keywords: Carpal tunnel syndrome, Pain catastrophizing scale, Patient satisfaction, Risk factors

\footnotetext{
* Correspondence: sebmos@rm.dk

1 Department of Orthopaedics, University Clinic for Hand, Hip and Knee

Surgery, Lægårdvej 12, 7500 Holstebro, Denmark

${ }^{2}$ Department of Clinical Medicine, Aarhus University, 8000 Aarhus, Denmark
}

(c) The Author(s). 2020 Open Access This article is distributed under the terms of the Creative Commons Attribution 4.0 International License (http://creativecommons.org/licenses/by/4.0/) which permits unrestricted use, distribution, and reproduction in any medium, provided you give appropriate credit to the original author(s) and the source, provide a link to the Creative Commons license, and indicate if changes were made. The Creative Commons Public Domain Dedication waiver (http://creativecommons.org/publicdomain/zero/1.0/) applies to the data made available in this article, unless otherwise stated. 


\section{Background}

Idiopathic carpal tunnel syndrome (CTS) is a common upper limb nerve compression disease [1]. CTS can lead to several symptoms such as tingling or numbness, pain, and reduced grip strength [2]. It appears mainly in middle-aged women [1, 3, 4], with an approximated gender ratio of 3:1 [5]. The European prevalence is estimated to be $1-7 \%[5,6]$, with an incidence of 1.8 per 1000 years [5], leading to roughly 300,000 operations per year in Germany [7]. Emphasizing the incidence of CTS, it is estimated that close to 1 million people annually need medical treatment of CTS in America [3]. Surgical decompression with either endoscopic carpal tunnel release (ECTR) or open carpal tunnel release (OCTR) is used to improve function and relieve symptoms [8] when conservative treatment (steroid injections and orthoses) of the hand is inadequate [9]. Although the outcome following carpal tunnel release (CTR) is mainly positive, symptoms remain or reoccur in $3-20 \%$ of cases [10, 11]. Several factors have been suggested to be predictive of negative surgical outcomes; smoking, bilateral CTS, low preoperative symptom severity, diabetes, older age, poor physical health, and poor mental health [12-14].

The use of patient reported outcome measures (PROMs) to evaluate the surgical outcome has increased. Furthermore, the overall patient satisfaction has been shown to predict the sick leave duration following CTR [15]. In a systematic review from 2017, 3 of 5 studies showed a significant correlation between patient satisfaction and psychological measures of depression and mental health in CTS patients [16]. Studies further show that selfreported depression is correlated to poorer self-evaluated hand function in patients suffering from trapeziometacarpal arthritis [17]. In CTS patients, preoperative hospital anxiety is associated with worse preoperative symptom severity [18]. Additionally, a worse score on the 5-item Mental Health interview has been associated to lower postoperative patient satisfaction [13]. These studies indicate the effect of psychological factors on different outcome measures including satisfaction. However, little attention has been drawn to the effect of pain catastrophizing (measured using the Pain Catastrophizing Scale (PCS)) on patient satisfaction following CTR. A study from 2010 on 120 patients with different hand diseases (carpal tunnel syndrome, trigger finger, and benign tumors) did not find a correlation between preoperative PCS and postoperative DASH scores [19]. Conversely, a newer study from 2014 on 256 patients with atraumatic hand disorders found an association between PCS and the Michigan Hand Outcome Questionnaire (MHOQ). The study showed worse scores on the MHOQ for patients with high PCS (PCS > 30) compared to patients with low PCS $(\mathrm{PCS} \leq 30)$ at baseline, and at 1- and 2-month followups [20].
To our knowledge, only one study has briefly examined the effect of PCS on patient satisfaction in CTS patients [21]. This retrospective study on 82 patients did not find an association between PCS and patient satisfaction in a univariate analysis and did not examine it further. Given the results from other studies indicating an effect of mental health and PCS on the outcome after treatment of hand disorders, this study aimed to further investigate the effect of PCS.

Based on demographic characteristics, PROMs, and with special attention to PCS, the purpose of this study was to identify risk factors for low patient-reported satisfaction following surgical treatment of idiopathic CTS with CTR. The main hypothesis of this study was that higher preoperative PCS scores increase the risk of low postoperative patient reported satisfaction.

\section{Methods}

Patients with nerve conduction verified Carpal Tunnel Syndrome (CTS) were recruited between February 11th 2011 and January 5th 2015 at the Department of Orthopaedics, Regional Hospital Holstebro. This prospective cohort consists of 732 hands from 714 patients treated surgically for CTS with either open carpal tunnel release (OCTR - 38\%) or endoscopic carpal tunnel release (ECTR - 62\%). Patients were asked to fill out a set of questionnaires preoperatively and 12 months postoperatively. The preoperative questionnaires included; a health-related quality of life assessment using EQ-5D, hand function using a translated and validated version of the Disabilities of the Arm, Shoulder and Hand questionnaire (DASH) $[22,23]$, and catastrophic thinking of pain using the Pain Catastrophizing Scale (PCS). The DASH questionnaire is a 30-item questionnaire used to measure patient reported disability through 30 statements on a 5-point Likert scale, where a higher score reflects more disability [24]. PCS is used to measure coping skills and negative feelings of pain through 13 statements with 4 possible options from 1 "not at all" to 4 "all the time" with a higher score reflecting higher catastrophic thinking [25]. The score can further be categorized as either high $(\mathrm{PCS}>30)$ or low $(\mathrm{PCS} \leq 30)$ [26]. Distal motor latency was registered following preoperative nerve conduction tests.

The 12-month postoperative questionnaire included the EQ-5D, DASH, and a question on patient satisfaction with 4 options ranging from 1 "I am dissatisfied" to 4 "I am very satisfied". We then pooled options 1 and 2 as low satisfaction and options 3 and 4 as high satisfaction.

\section{Patient demographics}

All patients with nerve conduction verified CTS were assessed for eligibility (714). The second operated hand was excluded from 18 bilateral patients to avoid 
statistical dependence, and 92 hands were excluded due to missing preoperative data on DASH, EQ-5D, and PCS. A further 205 hands were excluded due to missing 12-month postoperative data on DASH and EQ-5D, leaving 417 patients (64.5\% women) with a mean age of 58 years (range, 18-92 yrs.) for analysis. The exclusion of patients did not lead to statistically significant changes in preoperative baseline characteristics. Further patient characteristics before and after exclusion can be seen in Table 1.

The study was reviewed by the local research ethics committee, and no further specific approval was demanded because the study is an outcome study, which according to the Danish law,"Act on a Biomedical Research Ethics Committee System and the Processing of Biomedical Research Projects", Part 3 "Notification and Authorization: Questionnaire-based projects and register research projects shall only be notified to a regional committee if the project also involves human biological material." The study was registered in The Danish Data Protection Agency: jr. nr.: 2007-58-0010.

\section{Statistics}

Wilcoxon matched-pairs signed-rank test was used to test for difference in preoperative and postoperative DASH and EQ-5D scores due to non-normality. Logistic regression analysis and multiple logistic regression analysis were used to test predictors of low patient reported satisfaction following surgical treatment of CTS in Tables 2 and 3. This was done in four steps. Step 1 was crude logistic regressions of the associations between the variables of interest one by one and the dichotomous outcome high/ low satisfaction. Step 2 was to adjust for preoperative baseline characteristics; age, gender, and operation technique. Step 3 was to adjust for age, gender, operation technique, and further adjust for the other predictors of interest; PCS, EQ-5D, DASH, and distal motor latency. The 4th and final step was to examine multicollinearity in the models. We examined multicollinearity in the multivariate logistic regression models using variance inflation factors (VIF), finding no VIF $>2.02$. All statistical analyses were made using STATA, Version 15 IC (Stata Corp, College Station, TX, USA).

\section{Results}

When analyzing the patients as one group, we found a statistically significant improvement in both DASH and EQ$5 \mathrm{D}$ at the 12-month follow-up. The mean improvement in EQ-5D was 0.14 [95\% CI: 0.13-0.16] $(p<0.001)$, which was a change from 0.74 [ $95 \%$ CI: $0.72-0.76$ ] preoperatively to 0.89 [ $95 \%$ CI: $0.87-0.91] 12$ months postoperatively, which is more than the estimated minimal clinical important difference (MCID) of 0.10 [27]. DASH scores improved by 12.29 [95\% CI:10.65-13.90] $(p<0.001)$, which was a change from 24.88 [95\% CI:22.87-26.89] preoperatively to 12.60 [95\% CI,10.73-14.47] 12 months postoperatively, which is more than the MCID of 12 points for the Danish validated DASH [28].

The patients reporting low satisfaction at 12 months had a higher preoperative PCS score, lower EQ-5D, and higher DASH score. Further, the patients reporting low satisfaction had a tendency toward lower preoperative distal motor latency but with overlapping confidence intervals for the mean. There was no statistical difference in age and gender between patients reporting low satisfaction and patients reporting high satisfaction. Means and confidence intervals can be seen in Table 2 .

Table 3 shows the logistic regression models of the association between the possible predictive preoperative variables. After including both demographics (age, gender, operation technique, and living alone) and preoperative disability (PCS, EQ-5D, DASH, and distal motor latency) in the model, we found a statistically significant effect of preoperative PCS on patient reported satisfaction with $\mathrm{OR}=$ $1.05(p=0.022)$ for a 1-unit increase in preoperative PCS.

We did not find a statistically significant effect of EQ$5 \mathrm{D}(p=0.869)$, DASH $(p=0.076)$, distal motor latency $(p=0.067)$ age $(p=0.505)$, or gender $(p=0.222)$.

Table 1 Preoperative baseline characteristics with 95\% confidence intervals before and after exclusion

\begin{tabular}{|c|c|c|c|c|}
\hline & \multicolumn{2}{|c|}{ Baseline before exclusion $(N=732)$} & \multicolumn{2}{|c|}{ Baseline after exclusion $(N=417)$} \\
\hline & Mean & $95 \% \mathrm{Cl}$ & Mean & $95 \% \mathrm{Cl}$ \\
\hline Female $\%$ & $63.9 \%$ & . & $64.5 \%$ & . \\
\hline Age, years & 58. 0 & 56. 9-59. 1 & 58. 0 & 56. 5-59. 4 \\
\hline Female age, years & 57. 2 & 55. 8-58. 6 & 56.7 & 54. $9-58.5$ \\
\hline Male age, years & 59.5 & 57. 5-61. 4 & 60.4 & 58. $0-62.8$ \\
\hline DASH & 26. 1 & 24. $2-27.9$ & 25.4 & 23. $5-27.4$ \\
\hline$E Q-5 d$ & 0.74 & $0.72-0.76$ & 0.74 & $0.72-0.76$ \\
\hline PCS & 13.3 & 12. $3-14.3$ & 13. 0 & 11. 9-14. 1 \\
\hline Distal motor latency, m/s & 5.7 & $5.6-5.9$ & 5.7 & 5. 5-5. 9 \\
\hline
\end{tabular}

Preoperative data on patients before and after exclusion both preoperative and 12-months postoperative 
Table 2 Preoperative baseline characteristics for highly satisfied and lowly satisfied patients

\begin{tabular}{llllll}
\hline & \multicolumn{2}{l}{ High satisfaction } & & \multicolumn{2}{l}{ Low satisfaction } \\
\cline { 2 - 3 } & Mean & $95 \% \mathrm{Cl}$ & & Mean & $95 \% \mathrm{Cl}$ \\
\hline Female, \% & $66.0 \%$ & & & $60.1 \%$ & \\
Age, years & 55.8 & $53.8-57.7$ & & 56.2 & $51.6-60.9$ \\
DASH & 22.7 & $20.4-24.9$ & & 38.0 & $31.6-44.4$ \\
Eq-5d & 0.76 & $0.74-0.78$ & & 0.66 & $0.59-0.74$ \\
PCS & 11.2 & $10.0-12.4$ & & 19.6 & $16.0-23.3$ \\
Distal motor latency, $\mathrm{m} / \mathrm{s}$ & 5.70 & $5.46-5.93$ & & 5.13 & $4.72-5.56$ \\
\hline
\end{tabular}

Preoperative baseline characteristics with mean and $95 \%$ confidence intervals for patients reporting high satisfaction and patients reporting low satisfaction 12 months postoperative

Although the $p$-value related to the preoperative DASH score exceeded the 0.05 significance level, the $95 \%$ confidence interval for the odds ratio ranging from [1.00$1.05]$ indicates that there could be a tendency toward an increased risk of low patient reported satisfaction with an increased preoperative DASH score.

Table 4 shows an analysis of the risk of low satisfaction for patients with preoperative PCS $>30$ compared to patients with PCS $\leq 30$. Unadjusted and adjusted for demographics, we found an OR of 2.24 and 2.56 respectively for low satisfaction for patients with preoperative PCS $>30$ ( $p=0.005 \& p=0.003$ respectively). However, when further adjusting for preoperative DASH, EQ-5D, and distal motor latency, the OR dropped to 1.85 [95\% CI: 0.78-4.39], and was no longer significant.

Finally, Fig. 1 shows a scatter plot of the preoperative PCS and the preoperative DASH and EQ-5D scores. Correlation analysis using Spearman's rho shows a correlation of rho $=0.6135(p<0.001)$ and rho $=-0.4950$ $(p<0.001)$ for PCS and DASH, and PCS and EQ-5D respectively. This indicate that the patients with high preoperative PCS tend to score worse on both preoperative DASH and EQ-5D.

Since DASH and EQ-5D were collected both at baseline and 12 months postoperatively, we analyzed the effect of improvement in DASH and EQ-5D on the patient reported satisfaction after CTR. In the fully adjusted models, we found an OR for low patient reported satisfaction of 0.93 for a 1-unit increased improvement in DASH $(p<0.001)$ and an OR of 0.54 for a 0.1 -unit increased improvement in EQ-5D $(p<0.001)$. For both

Table 3 The association between baseline characteristics and patient reported satisfaction

\begin{tabular}{|c|c|c|c|}
\hline \multirow[t]{2}{*}{ Preoperative } & \multicolumn{3}{|c|}{ Odds ratio for low patient reported satisfaction following CTR } \\
\hline & Odds ratio & $95 \% \mathrm{Cl}$ & $p$ \\
\hline \multicolumn{4}{|l|}{$\overline{P C S}$} \\
\hline Unadjusted $^{\mathrm{a}}$ & 1. 08 & 1. $05-1.11$ & $<0.001^{*}$ \\
\hline+ Demographics $^{b}$ & 1. 09 & 1. $06-1.12$ & $<0.001^{*}$ \\
\hline + Disability ${ }^{c}$ & 1. 05 & 1. $01-1.10$ & $0.022^{*}$ \\
\hline \multicolumn{4}{|l|}{ EQ-5D } \\
\hline Unadjusted $^{\mathrm{a}}$ & 0.13 & $0.03-0.51$ & $0.004^{*}$ \\
\hline+ Demographics $^{b}$ & 0.10 & $0.02-0.46$ & $0.003^{*}$ \\
\hline + Disability ${ }^{c}$ & 0.82 & $0.09-7.82$ & 0.869 \\
\hline \multicolumn{4}{|l|}{ DASH } \\
\hline Unadjusted $^{\mathrm{a}}$ & 1. 04 & 1. $02-1.05$ & $<0.001^{*}$ \\
\hline+ Demographics $^{b}$ & 1. 04 & 1. $02-1.06$ & $<0.001^{*}$ \\
\hline+ Disability $^{c}$ & 1. 02 & 1. $00-1.05$ & 0.056 \\
\hline \multicolumn{4}{|l|}{ Distal motor latency } \\
\hline Unadjusted $^{\mathrm{a}}$ & 0.83 & $0.68-1.01$ & 0.063 \\
\hline + Demographics ${ }^{b}$ & 0.78 & $0.63-0.98$ & $0.030^{*}$ \\
\hline+ Disability $^{c}$ & 0.75 & $0.55-1.02$ & 0.067 \\
\hline \multicolumn{4}{|l|}{ Living alone } \\
\hline Unadjusted $^{\mathrm{a}}$ & 0.70 & $0.35-1.41$ & 0.320 \\
\hline+ Demographics ${ }^{b}$ & 0.69 & $0.33-1.44$ & 0.321 \\
\hline+ Disability $^{c}$ & 0.36 & $0.11-1.81$ & 0.092 \\
\hline
\end{tabular}

Multiple logistic regression analysis on the association between baseline characteristics and patient reported satisfaction 12 months postoperative *Denotes statistical significance

aUnadjusted crude association on odds ratio for low patient reported satisfaction

${ }^{\mathrm{b}}$ Adjusted for age, gender, living alone and operation technique

${ }^{c}$ Adjusted for age, gender, operation technique, living alone and preoperative scores (PCS, EQ-5D, DASH and distal motor latency) 
Table 4 The risk of low patient reported satisfaction for patients with preoperative PCS $>30$

\begin{tabular}{|c|c|c|c|}
\hline \multirow[t]{2}{*}{ Preoperative } & \multicolumn{3}{|c|}{ Odds ratio for low patient reported satisfaction following CTR } \\
\hline & Odds ratio & $95 \% \mathrm{Cl}$ & $p$ \\
\hline \multicolumn{4}{|l|}{ PCS $>30$} \\
\hline Unadjusted $^{a}$ & 2. 24 & 1. $27-3.96$ & $0.005^{*}$ \\
\hline+ Demographics $^{\mathrm{b}}$ & 2. 56 & 1. $38-4.74$ & $0.003^{*}$ \\
\hline+ Disability $^{c}$ & 1.85 & $0.78-4.39$ & 0.165 \\
\hline
\end{tabular}

DASH and EQ-5D, it shows that the risk of low patient reported satisfaction is reduced with increased improvement.

\section{Discussion}

We found a significant improvement above the MCIDs in patient disability measured by DASH, and in quality of life measured by EQ-5D, from baseline to the 12-month follow-up after CTR. A total of $84.2 \%$ of the patients felt either satisfied or very satisfied 12 months after the operation. Higher preoperative PCS had a statistically significant negative influence on patient reported satisfaction. Furthermore, we found a trend towards a negative predictive effect of low preoperative distal motor latency and a high preoperative DASH score. There was no predictive effect of age, gender, or preoperative EQ-5D, on postoperative patient satisfaction.

In secondary analyses, we found that lower improvements in both postoperative DASH and EQ-5D increased the risk of low patient reported satisfaction, Table 5.

\section{Age and gender}

Although we did not find age and gender to be a predictor of patient satisfaction, previous studies have shown diverse findings. In 1998, Atroshi et al. found higher age to be a risk factor for low patient reported satisfaction 6 months after OCTR in a study on 128 Swedish patients (mean age 51 years, range 21-94) [29]. On the contrary, a Taiwanese study including 58 patients (mean age 50.6 years, $\mathrm{SD}=10.54$ ) did not find a predictive effect of age on postoperative patient
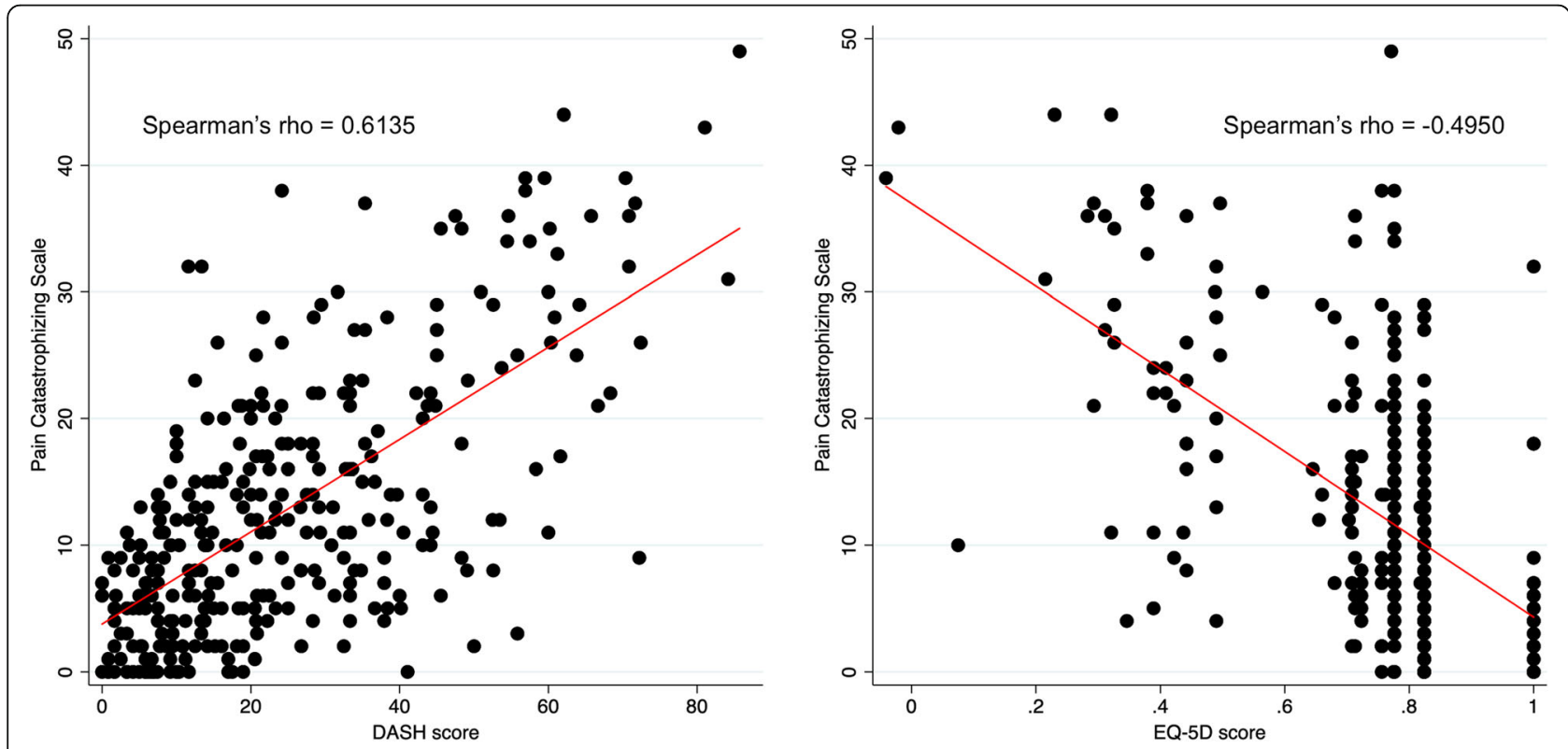

Fig. 1 Preoperative PCS against DASH and EQ-5D. Left side: Scatterplot of preoperative PSC and DASH score showing a positive correlation between PCS and DASH score with Spearman's rho $=0.6135$. The red line illustrates a linear line of best fit. Right side: Scatterplot of preoperative PSC and EQ5D score showing a negative correlation between PCS and EQ-5D score with Spearman's rho $=-0.4950$. The red line illustrates a linear line of best fit 
Table 5 The association of change in DASH and EQ-5D and low patient reported satisfaction

\begin{tabular}{|c|c|c|c|}
\hline \multirow[t]{2}{*}{ Change } & \multicolumn{3}{|c|}{ Odds ratio for low patient reported satisfaction following CTR } \\
\hline & Odds ratio & $95 \% \mathrm{Cl}$ & $p$ \\
\hline \multicolumn{4}{|l|}{$\mathrm{DASH}^{\mathrm{d}}$} \\
\hline Unadjusted & 0.93 & $0.90-0.96$ & $<0.001^{*}$ \\
\hline+ Demographics $^{a}$ & 0.93 & $0.91-0.96$ & $<0.001^{*}$ \\
\hline+ Disability ${ }^{b}$ & 0.92 & $0.89-0.95$ & $<0.001^{*}$ \\
\hline \multicolumn{4}{|l|}{$E Q 5 D^{e}$} \\
\hline Unadjusted & 0.54 & $0.43-0.67$ & $<0.001^{*}$ \\
\hline+ Demographics $^{a}$ & 0.54 & $0.43-0.68$ & $<0.001^{*}$ \\
\hline + Disability ${ }^{c}$ & 0.53 & $0.40-0.69$ & $<0.001^{*}$ \\
\hline
\end{tabular}

Multiple logistic regression analysis on the association of change in DASH and EQ-5D and low patient reported satisfaction 12 months postoperative *Denotes statistical significance

anadjusted crude association on odds ratio for low patient reported satisfaction

${ }^{\mathrm{b}}$ Adjusted for age, gender, living alone and operation technique

'Adjusted for age, gender, operation technique, living alone and preoperative variables (PCS, EQ-5D and distal motor latency)

${ }^{\mathrm{d}}$ The effect of a 1 - unit increase in DASH improvement

${ }^{\mathrm{e}}$ The effect of a 0. 1- unit increase in Eq-5d improvement

satisfaction [30]. The effect of age has also been examined with other outcomes such as return to work, disability, and symptom relief, with mixed findings showing no effect of age on return to work [31], QuickDASH improvement [12], or disability [32]. But higher age has been found to have a negative effect on symptom relief 6 months after CTR [33].

As with age, we did not find a similar effect of gender on patient satisfaction as Atroshi et al. [29]. However, a Danish prospective cohort study on 101 patients did find males to be less satisfied than females 2 months after ECTR [34]. Additionally, gender had no effect in studies of return to work [31], QuickDASH improvement [12], disability [32], or symptom relief [33]. With the mixed results from this study and previous studies in mind, the effects of both age and gender still seem unclear.

\section{Distal motor latency}

We found that lower preoperative distal motor latency might increase the risk of low patient reported satisfaction 12 months after CTR. The same has been shown in a study measuring patient satisfaction 6 months after CTR [29], indicating that preoperative distal motor latency could be a valuable tool in predicting postoperative patient satisfaction. This may also reflect that patients with low distal motor latency have less to gain after an operation compared to patients with more severe nerve compression. Conversely, a Danish study on 75 patients found that higher distal motor latency, indicating more severe median nerve compression, led to longer sick leave from work following CTR [35].

\section{PCS}

In this study, preoperative PCS was found to have a predictive effect on the 12-month postoperative patient satisfaction, with a higher (worse) PCS increasing the risk of low postoperative patient satisfaction. Dissimilar to our results, a retrospective study from 2008 with comparable age and gender distribution on 82 (53 women / 29 men) American patients (mean age 61 years, range 34-92), did not find a correlation between PCS and patient satisfaction after a minimum of 2 years [21]. Additionally, another American study on 120 patients (69 women / 51 men) with a mean age of 61 years (range 18-86), showed no correlation between postoperative PCS and DASH, but a correlation between PCS and pain at the time of suture removal (10-14 days after surgery) in a cohort of patients treated for CTS $(n=39)$, trigger finger $(n=$ 65) and benign tumors $(n=16)$ [19]. This difference in results may reflect the different study designs and number of patients.

The effects of other psychological measures have been examined in previous studies with various results. "The Hospital Anxiety and Depression Score" (HADS), is a reliable instrument used to detect and evaluate severity of depression and anxiety [36]. An English study from 2005 showed no difference in patient satisfaction and Boston Carpal Tunnel Questionnaire (BCTQ) between patients with high and low HADS 6 months after CTR surgery [18]. Mental health status measured by subscales from the SF-36 has shown that worse mental health status predicts lower postoperative patient satisfaction 18 months after CTR [13]. Similarly, a 13-study systematic review found that a worse mental health status leads to longer sick leave after CTR [37]. Additionally, a weak correlation between depression and patient satisfaction was shown in an 8-study systematic review [16], where 3 in 5 studies on patients treated with CTR established a significant negative association between patient 
satisfaction and psychological factors measured using the Centers of the Epidemiological Study of Depression Instrument (CES-D), 5-item Mental Health Interview, and HADS.

The results from the present study indicate a predictive negative effect of higher preoperative PCS on patient reported satisfaction 12 months after CTR. If possible, clinicians should examine both the patient's physicaland mental health status and discuss these parameters with the patient before performing CTR. PCS might be a useful tool for doing so even though this study did not find a statistically significant increased risk when dividing patients in PCS groups using a score $\geq 30$ as the cutoff value [26]. We believe that these results call for further studies on the predictive effects of PCS.

\section{Considerations}

We used the DASH score as a measure of patient disability. Since DASH targets both the arm, shoulder and hand, other injuries not related to CTS might affect the validity of DASH as an instrument to measure disability related to CTS. The use of a CTS related disability questionnaire e.g. the Boston Carpal Tunnel Questionnaire, might have increased the accuracy of the measurements.

Another consideration is the exclusion of 315 (43\%) patients due to missing data. $43 \%$ is a large number of excluded patients, which potentially could lead to bias. We did however not see a change in baseline characteristics after exclusion of patients without a full dataset.

Several other factors, which were not investigated in this study, such as lower income [31], active smoking status [12, 38], and higher alcohol consumption [13, 38], have been shown to negatively affect the patients' outcome after CTR. Therefore, it would be of great interest to include these in statistical models on the predictive effect of PCS on patient satisfaction.

We used a 4-item Likert scale to examine patient satisfaction using one statement. An English study with 810 patients examined "The Friends and Family Test" (FFT), which is a variation of the "Net Promoter Score" (NPS) used to measure overall patient satisfaction. They found the FFT to be correlated to patient satisfaction, hospital experience, and functional outcome [39]. It would be interesting to examine the possible predictive effect of PCS on FFT. Given FFT's correlation to both satisfaction and function, a possible association between PCS and FFT would enable practitioners and surgeons to counsel the patient's potential outcome after CTR, not only based on satisfaction, but also as a surrogate marker of functional outcome.

\section{Conclusion}

CTR is an effective treatment for carpal tunnel syndrome with high patient satisfaction and improvement after 12 months in both DASH score and EQ-5D. Higher preoperative PCS seems to have a negative effect on postoperative patient reported satisfaction after CTR. Further studies on patient satisfaction should include additional information on patient smoking habits, alcohol consumption, BMI, diabetes, and income, to strengthen the explanatory power.

\section{Abbreviations}

BCTQ: Boston Carpal Tunnel Questionnaire; CES-D: Centers of the Epidemiological Study of Depression Instrument; CTR: Carpal tunnel release; CTS: Carpal tunnel syndrome; DASH: Disabilities of the Arm Shoulder and Hand questionnaire; ECTR: Endoscopic carpal tunnel release; FFT: The Friends and Family Test; HADS: Hospital anxiety and depression scale; MCID: Minimal clinical important difference; MHOQ: Michigan Hand Outcome Questionnaire; NPS: Net Promotor Score; OCTR: Open carpal tunnel release; VIF: Variance inflation factor

\section{Acknowledgements \\ None.}

\section{Authors' contributions}

SBM: Data analysis, interpreting results, statistical analysis, drafting and editing manuscript. MS: Study design, data collection, interpreting results and editing manuscript. TBH: Study design, data collection, interpreting results and editing manuscript. All authors read and approved the final manuscript.

\section{Funding}

This study did not receive any grants or funding.

\section{Availability of data and materials}

The datasets used and analyzed during the current study are available from the corresponding author on reasonable request.

\section{Ethics approval and consent to participate}

The patients were informed about the research study and data collection as they completed the questionnaires in relation to their booking for surgical treatment for carpal tunnel syndrome. At this time, they gave their verbal consent to the examiner. Prior to study initiation, the protocol was reviewed by the local research ethics committee, and no specific approval was demanded because the study is a quality assurance study, which according to the Danish law "Act on a Biomedical Research Ethics Committee System and the Processing of Biomedical Research Projects", Part 3 "Notification and Authorization: Questionnaire-based projects and register research projects shall only be notified to a regional committee if the project also involves human biological material."

Consent for publication

Not applicable.

\section{Competing interests}

The authors declare that they have no competing interests.

Received: 26 July 2019 Accepted: 10 January 2020

Published online: 18 January 2020

\section{References}

1. Aroori S, Spence RA. Carpal tunnel syndrome. Ulster Med J. 2008;77(1):6-17.

2. Middleton SD, Anakwe RE. Carpal tunnel syndrome. BMJ (Clinical research ed). 2014;349:96437.

3. Tanaka S, Wild DK, Seligman PJ, Behrens V, Cameron L, Putz-Anderson V. The US prevalence of self-reported carpal tunnel syndrome: 1988 National Health Interview Survey data. Am J Public Health. 1994;84(11):1846-8.

4. Mondelli M, Giannini F, Giacchi M. Carpal tunnel syndrome incidence in a general population. Neurology. 2002;58(2):289-94.

5. Bongers FJ, Schellevis FG, van den Bosch WJ, van der Zee J. Carpal tunnel syndrome in general practice (1987 and 2001): incidence and the role of occupational and non-occupational factors. Br J Gen Pract. 2007;57(534):36-9. 
6. Atroshi I, Gummesson C, Johnsson R, Ornstein E, Ranstam J, Rosen I. Prevalence of carpal tunnel syndrome in a general population. JAMA. 1999; 282(2):153-8.

7. Giersiepen K, Spallek M. Carpal tunnel syndrome as an occupational disease. Dtsch Arztebl Int. 2011;108(14):238-42.

8. Brown RA, Gelberman RH, Seiler JG 3rd, Abrahamsson SO, Weiland AJ Urbaniak JR, Schoenfeld DA, Furcolo D. Carpal tunnel release. A prospective, randomized assessment of open and endoscopic methods. J Bone Joint Surg Am. 1993;75(9):1265-75.

9. Cagle PJ Jr, Reams M, Agel J, Bohn D. An outcomes protocol for carpal tunnel release: a comparison of outcomes in patients with and without medical comorbidities. J Hand Surg. 2014;39(11):2175-80.

10. Tung TH, Mackinnon SE. Secondary carpal tunnel surgery. Plast Reconstr Surg. 2001;107(7):1830-43 quiz 1844,1933.

11. Cobb TK, Amadio PC. Reoperation for carpal tunnel syndrome. Hand Clin. 1996;12(2):313-23.

12. Duckworth AD, Jenkins PJ, Roddam P, Watts AC, Ring D, McEachan JE. Pain and carpal tunnel syndrome. J Hand Surg. 2013;38(8):1540-6.

13. Katz JN, Losina E, Amick BC 3rd, Fossel AH, Bessette L, Keller RB. Predictors of outcomes of carpal tunnel release. Arthritis Rheum. 2001;44(5):1184-93.

14. Tan JS, Tan AB. Outcomes of open carpal tunnel releases and its predictors: a prospective study. Hand Surg. 2012;17(3):341-5.

15. Parot-Schinkel E, Roquelaure $Y, H a$ C, Leclerc A, Chastang JF, Raimbeau G, Chaise F, Descatha A. Factors affecting return to work after carpal tunnel syndrome surgery in a large French cohort. Arch Phys Med Rehabil. 2011; 92(11):1863-9.

16. Park JW, Gong HS, Rhee SH, Kim J, Lee YH, Baek GH. The effect of psychological factors on the outcomes of carpal tunnel release: a systematic review. J Hand Surg Asian Pac Vol. 2017;22(2):131-7.

17. Calfee R, Chu J, Sorensen A, Martens E, Elfar J. What is the impact of comorbidities on self-rated hand function in patients with symptomatic trapeziometacarpal arthritis? Clin Orthop Relat Res. 2015;473(11):3477-83.

18. Hobby JL, Venkatesh R, Motkur P. The effect of psychological disturbance on symptoms, self-reported disability and surgical outcome in carpal tunnel syndrome. J Bone Joint Surg Br. 2005;87(2):196-200.

19. Vranceanu AM, Jupiter JB, Mudgal CS, Ring D. Predictors of pain intensity and disability after minor hand surgery. J Hand Surg. 2010;35(6):956-60.

20. London DA, Stepan JG, Boyer MI, Calfee RP. The impact of depression and pain catastrophization on initial presentation and treatment outcomes for atraumatic hand conditions. J Bone Joint Surg Am. 2014;96(10):806-14.

21. Lozano Calderon SA, Paiva A, Ring D. Patient satisfaction after open carpal tunnel release correlates with depression. J Hand Surg. 2008;33(3):303-7.

22. Herup A, Merser S, Boeckstyns M. Validation of questionnaire for conditions of the upper extremity. Ugeskr Laeger. 2010;172(48):3333-6.

23. Schonnemann JO, Larsen K, Hansen TB, Soballe K. Reliability and validity of the Danish version of the disabilities of arm, shoulder, and hand questionnaire in patients with fractured wrists. J Plast Surg Hand Surg. 2011;45(1):35-9.

24. Hudak PL, Amadio PC, Bombardier C. Development of an upper extremity outcome measure: the DASH (disabilities of the arm, shoulder and hand) [corrected]. The upper extremity collaborative group (UECG). Am J Ind Med. 1996;29(6):602-8

25. Osman A, Barrios FX, Gutierrez PM, Kopper BA, Merrifield T, Grittmann L. The pain catastrophizing scale: further psychometric evaluation with adult samples. J Behav Med. 2000;23(4):351-65.

26. Sullivan MJ. The pain catastrophizing scale - user manual. 5th ed. Montreal: McGill University; 2009.

27. Chen $P$, Lin KC, Liing RJ, Wu CY, Chen CL, Chang KC. Validity, responsiveness, and minimal clinically important difference of EQ-5D-5L in stroke patients undergoing rehabilitation. Quality of life research: an international journal of quality of life aspects of treatment, care and rehabilitation. 2016;25(6):1585-96.

28. Lundquist CB, Dossing K, Christiansen DH. Responsiveness of a Danish version of the disabilities of the arm, shoulder and hand (DASH) questionnaire. Danish Med J. 2014;61(4):A4813.

29. Atroshi I, Johnsson R, Ornstein E. Patient satisfaction and return to work after endoscopic carpal tunnel surgery. J Hand Surg. 1998;23(1):58-65.

30. Chen AC, Wu MH, Cheng CY, Chan YS. Outcomes and satisfaction with endoscopic carpal tunnel releases and the predictors - a retrospective cohort study. Open Orthop J. 2016;10:757-64.
31. Conzen C, Conzen M, Rubsamen N, Mikolajczyk R. Predictors of the patientcentered outcomes of surgical carpal tunnel release - a prospective cohort study. BMC Musculoskelet Disord. 2016;17:190

32. Edgell SE, McCabe SJ, Breidenbach WC, LaJoie AS, Abell TD. Predicting the outcome of carpal tunnel release. J Hand Surg. 2003;28(2):255-61.

33. Fakhouri F, Alsukhni RA, Altunbi B, Hawoot Z, Dabbagh R. Factors correlated with unfavorable outcome after carpal tunnel release surgery. Asian J Neurosurg. 2017;12(4):670-3.

34. Hansen TB, Larsen K. Age is an important predictor of short-term outcome in endoscopic carpal tunnel release. J Hand Surg Eur Vol. 2009;34(5):660-4

35. Hansen TB, Dalsgaard J, Meldgaard A, Larsen K. A prospective study of prognostic factors for duration of sick leave after endoscopic carpal tunnel release. BMC Musculoskelet Disord. 2009;10:144.

36. Zigmond AS, Snaith RP. The hospital anxiety and depression scale. Acta Psychiatr Scand. 1983;67(6):361-70.

37. Peters S, Johnston V, Hines S, Ross M, Coppieters M. Prognostic factors for return-to-work following surgery for carpal tunnel syndrome: a systematic review. JBI Database System Rev Implement Rep. 2016;14(9):135-216.

38. Turner A, Kimble F, Gulyas K, Ball J. Can the outcome of open carpal tunnel release be predicted?: a review of the literature. ANZ J Surg. 2010;80(1-2):50-4

39. Stirling P, Jenkins PJ, Clement ND, Duckworth AD, McEachan JE. The net promoter scores with friends and family test after four hand surgery procedures. J Hand Surg Eur Vol. 2018. https://doi.org/10.1177/ 1753193418819686

\section{Publisher's Note}

Springer Nature remains neutral with regard to jurisdictional claims in published maps and institutional affiliations.
Ready to submit your research? Choose BMC and benefit from:

- fast, convenient online submission

- thorough peer review by experienced researchers in your field

- rapid publication on acceptance

- support for research data, including large and complex data types

- gold Open Access which fosters wider collaboration and increased citations

- maximum visibility for your research: over $100 \mathrm{M}$ website views per year

At $\mathrm{BMC}$, research is always in progress.

Learn more biomedcentral.com/submissions 